\title{
Recalcitrant Dissecting Cellulitis of the Scalp
}

\section{Treated Successfully with Adalimumab with Hair Regrowth: A Case Report}

\author{
Adel Alsantali (1D' \\ Basel Almalki $\mathbb{D D}^{2}$ \\ Abdullah Alharbi ${ }^{3}$ \\ 'Department of Dermatology, Hair \\ Disorder Unit, King Fahad Armed Forces \\ Hospital, Jeddah, Saudi Arabia; \\ ${ }^{2}$ Department of Dermatology, King \\ Abdulaziz Medical City, Ministry of \\ National Guard, Jeddah, Saudi Arabia; \\ ${ }^{3}$ Department of Pathology, King Fahad \\ Armed Forces Hospital, Jeddah, Saudi \\ Arabia
}

\begin{abstract}
Dissecting cellulitis (DC) of the scalp or perifolliculitis capitis abscedens et suffodiens is a rare chronic inflammatory condition of the scalp manifested by perifollicular pustules, nodules, abscesses and sinuses that result into scarring alopecia. Treatment of DC is challenging and often disappointing. We report a 38-year-old male patient with DC for 5 years, and multiple topical and systemic therapies had shown poor effect. This patient achieved excellent response to adalimumab with hair regrowth.
\end{abstract}

Keywords: dissecting cellulitis, perifolliculitis capitis abscedens et suffodiens, adalimumab, TNF- $\alpha$ inhibitor

\section{Introduction}

Dissecting cellulitis (DC) of the scalp, also known as perifolliculitis capitis abscedens et suffodiens, is a rare chronic inflammatory condition that results in scarring alopecia. It commonly affects young African-American men. It presents as firm or fluctuant tender nodules usually over the posterior vertex and upper occiput, with possible formation of interconnecting draining sinuses and abscesses. ${ }^{1}$ Spontaneous drainage of purulent foul-smelling discharge is commonly seen as well. ${ }^{2}$ Finally, scarring alopecia of the overlying skin and keloids develop.

The pathogenesis of this disorder is linked to the occlusion of the pilosebaceous unit and follicular hyperkeratosis with subsequent follicular dilatation and rupture that result in neutrophilic and granulomatous inflammatory response. Additionally, bacterial infections have been implicated in the pathogenesis of DC, with Staphylococcus epidermidis, Propionibacterium acnes, Staphylococcus aureus being the most commonly isolated. ${ }^{1}$

Treatment of DC is challenging and often disappointing. There are multiple treatment options for DC with varying response and efficacy. The commonly used agents are systemic antibiotics, oral isotretinoin, dapsone, zinc sulphate, and intralesional triamcinolone acetate. Photodynamic therapy and surgical excision have been used in resistant cases. ${ }^{3,4}$ Recently, few reports have been published about the use of tumor necrosis factor $(\mathrm{TNF}-\alpha)$ inhibitors in DC with promising results. ${ }^{5}$ Herein, we report a case of recalcitrant dissecting cellulitis of the scalp successfully treated with adalimumab.

Correspondence: Adel Alsantali Department of Dermatology, Hair Disorder Unit, King Fahad Armed Forces Hospital, P.O. Box 53893, Jeddah, 21593, Saudi Arabia

Email santli26@hotmail.com

\section{Case Report}

A 38-year-old male patient presented with 5-year history of inflammatory, boggy, fluctuant nodules over the upper occiput with recurrent foul-smelling discharge 
(Figure 1). A scalp punch biopsy showed epidermal hyperkeratosis, marked neutrophilic infiltrate of the hair follicles and deep dermis, and focal areas with
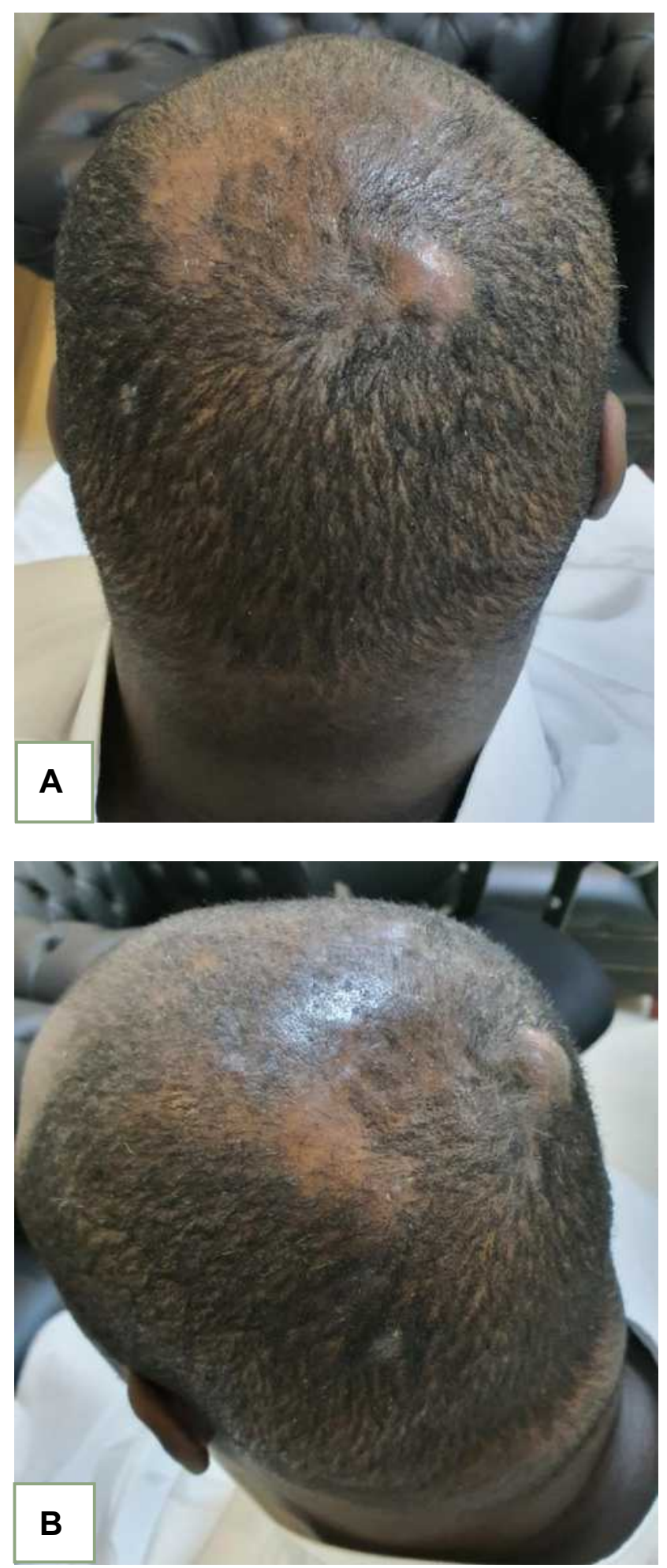

Figure I The patient with fluctuant, tender nodules with overlying alopecia. (A and B) Posterior and lateral views to show enlarged nodules in the scalp. multinucleated giant cells and histocytes (foreign body giant cell reaction) (Figure 2). A diagnosis of DC was made based on the findings of the clinical and histopathological examinations. The patient was initially treated with several topical and systemic antibiotics (clindamycin, doxycycline, and amoxicillin/clavulanic acid) with no improvement. After that, he was started on isotretinoin for 17 months, with dose escalation to $1 \mathrm{mg} / \mathrm{kg}$ ( $80 \mathrm{mg} /$ day). His disease activity was partially controlled with isotretinoin, but it was discontinued because he could not tolerate the side effect of severe dryness. After stopping isotretinoin, his disease relapsed again. The patient had purified protein derivative skin test, hepatitis serology, chemistry and chest X-ray, which all were within normal. After that,

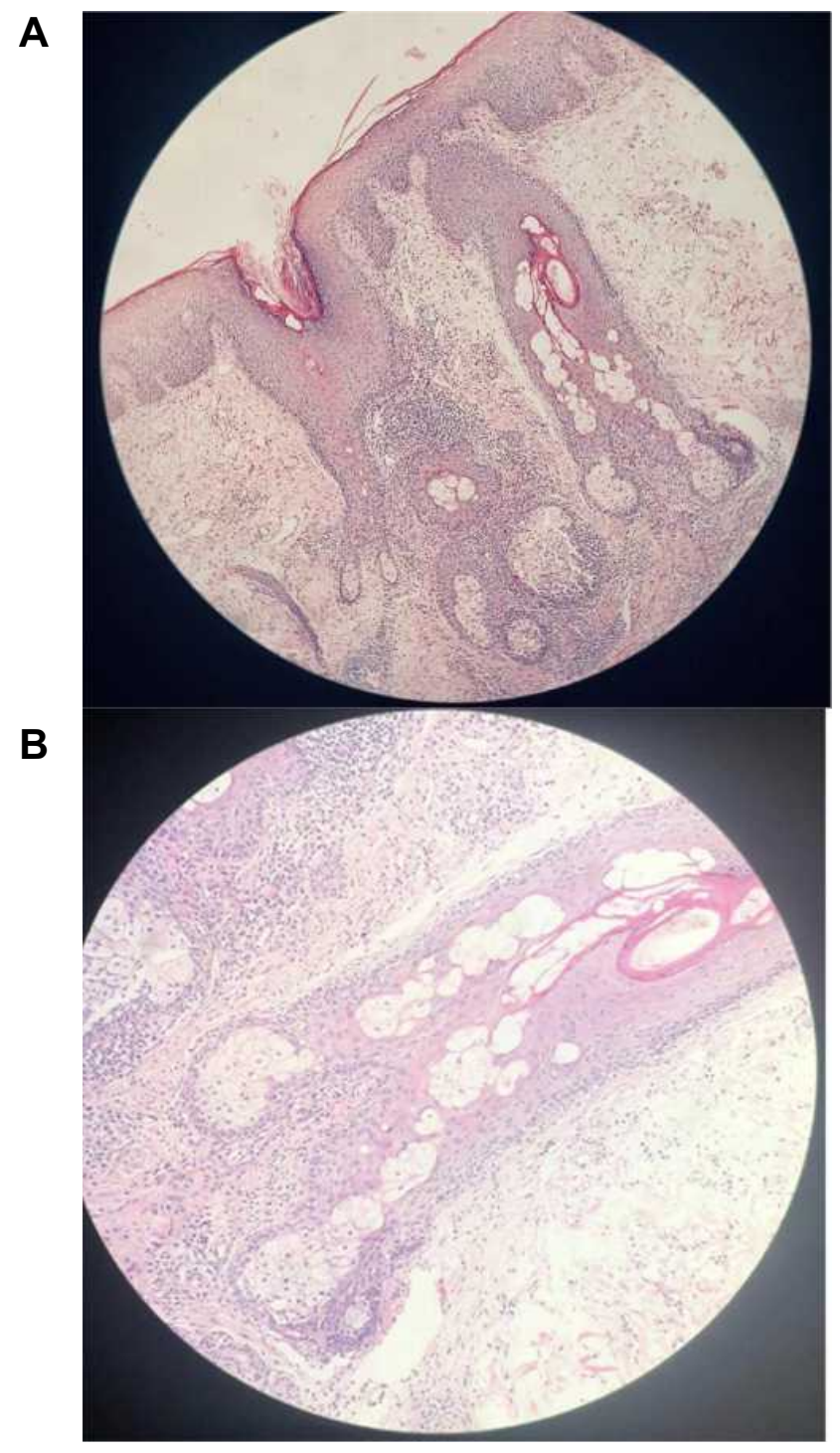

Figure 2 The scalp biopsy showing marked neutrophilic infiltrate of the hair follicles and deep dermis at low (A) and high (B) maginification. 


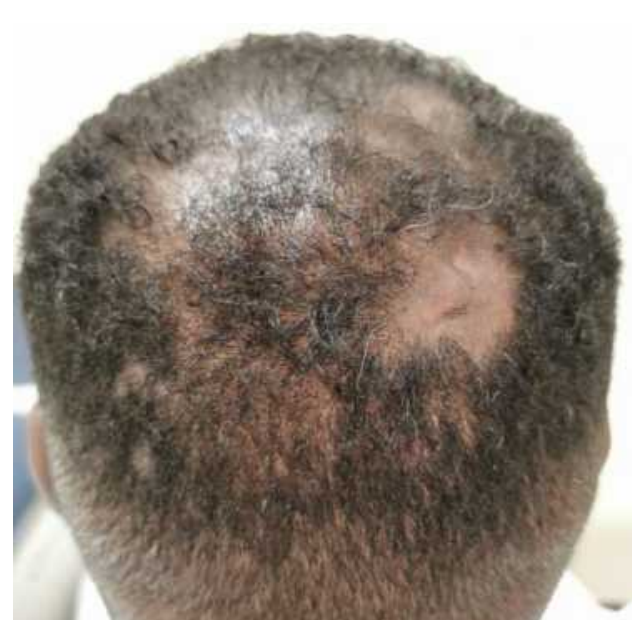

A

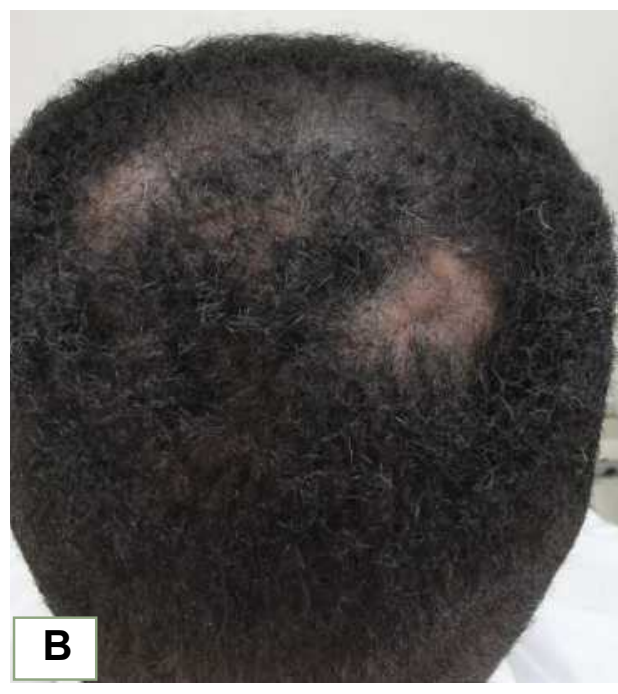

Figure 3 (A) Before treatment. (B) After 2 months of therapy showing partial hair regrowth.

adalimumab was started $80 \mathrm{mg}$ on day 0 , then $40 \mathrm{mg}$ on day 7 , and $40 \mathrm{mg}$ weekly thereafter. Excellent response was noted after 1 month of therapy. The patient reported less pain and no more discharge. At 2 months follow-up, decreased swelling and areas of hair regrowth were noted which is unusual in the primary cicatricial alopecias (Figure 3). The patient continues to receive $40 \mathrm{mg}$ adalimumab weekly.

\section{Discussion}

Dissecting cellulitis is neutrophilic scarring alopecia with chronic and relapsing course. Treatment of DC is often challenging. Oral antibiotics are typically used as initial management and have variable outcomes. The commonly used antibiotics are doxycycline, azithromycin, ciprofloxacin and the combination of rifampin with clindamycin. Their efficacy is hypothesized to be secondary to their anti-inflammatory properties. ${ }^{3}$ Isotretinoin is a frequently used option. In one systematic review of refractory DC, isotretinoin was prescribed for $53 \%$ of the cases with significant response seen in $54 \%$ of the case. However, relapse was common with relapse rate of $19 \% .^{4}$ The usual dose of isotretinoin is $0.5-1 \mathrm{mg} / \mathrm{kg}$, and the response is typically seen within 3 months; however, the duration of therapy is still controversial. Several antibiotics were used for our patient but with no significant improvement. However, he had good response with isotretinoin, although he relapsed after discontinuation.

Adalimumab is TNF- $\alpha$ inhibitor that has been increasingly used in various dermatological conditions, like psoriasis, and more recently in hidradenitis suppurativa (HS) and pyoderma gangrenosum with promising results. ${ }^{6}$ HS shares similar pathogenesis to $\mathrm{DC}$, therefore providing a justification to use adalimumab in DC. Few cases of DC treated with TNF- $\alpha$ inhibitors have been reported with good outcome in majority of the cases. ${ }^{5,7}$ Sukhatme et al reported a case of DC which had excellent response to adalimumab with hair regrowth. ${ }^{8}$ Likewise, our patient had hair regrowth after 2 months of therapy. The hair regrowth is unusual result to be seen after treatment of this type of primary scarring alopecia. Given these promising results of adalimumab in DC, larger controlled studies are needed to support these observations.

\section{Patient Consent}

The authors certify that they have obtained all appropriate patient consent forms. Patient gave written informed consent for publication of clinical information and photographs. Institutional approval is not required for this case study.

\section{Disclosure}

The authors report no conflicts of interest in this work.

\section{References}

1. Badaoui A, Reygagne P, Cavelier-Balloy B, et al. Dissecting cellulitis of the scalp: a retrospective study of 51 patients and review of literature. $B r \quad J$ Dermatol. 2016;174(2):421-423. doi:10.1111/ bjd. 13999

2. Whiting DA. Cicatricial alopecia: clinico-pathological findings and treatment. Clin Dermatol. 2001;19(2):211-225. doi:10.1016/S0738081X(00)00132-2 
3. Scheinfeld N. Dissecting cellulitis (Perifolliculitis Capitis Abscedens et Suffodiens): a comprehensive review focusing on new treatments and findings of the last decade with commentary comparing the therapies and causes of dissecting cellulitis to hidradenitis suppurativa. Dermatol Online J. 2014;20(5):22692.

4. Thomas J, Aguh C. Approach to treatment of refractory dissecting cellulitis of the scalp: a systematic review. $J$ Dermatolog Treat. 2019;1-6.

5. Takahashi T, Yamasaki K, Terui $\mathrm{H}$, et al. Perifolliculitis capitis abscedens et suffodiens treatment with tumor necrosis factor inhibitors: a case report and review of published cases. $J$ Dermatol. 2019;46(9):802-807. doi:10.1111/1346-8138.14998
6. Traczewski P, Rudnicka L. Adalimumab in dermatology. Br J Clin Pharmacol. 2008;66(5):618-625. doi:10.1111/j.1365-2125.20 08.03263.x

7. Brandt HR, Malheiros AP, Teixeira MG, et al. Perifolliculitis capitis abscedens et suffodiens successfully controlled with infliximab. $\mathrm{Br}$ $J$ Dermatol. 2008;159(2):506-507. doi:10.1111/j.1365-2133.200 8.08674.x

8. Sukhatme SV, Lenzy YM, Gottlieb AB. Refractory dissecting cellulitis of the scalp treated with adalimumab. J Drugs Dermatol. 2008;7 (10):981-983.

\section{Publish your work in this journal}

Clinical, Cosmetic and Investigational Dermatology is an international, peer-reviewed, open access, online journal that focuses on the latest clinical and experimental research in all aspects of skin disease and cosmetic interventions. This journal is indexed on CAS.
The manuscript management system is completely online and includes a very quick and fair peer-review system, which is all easy to use. Visit http://www.dovepress.com/testimonials.php to read real quotes from published authors. 